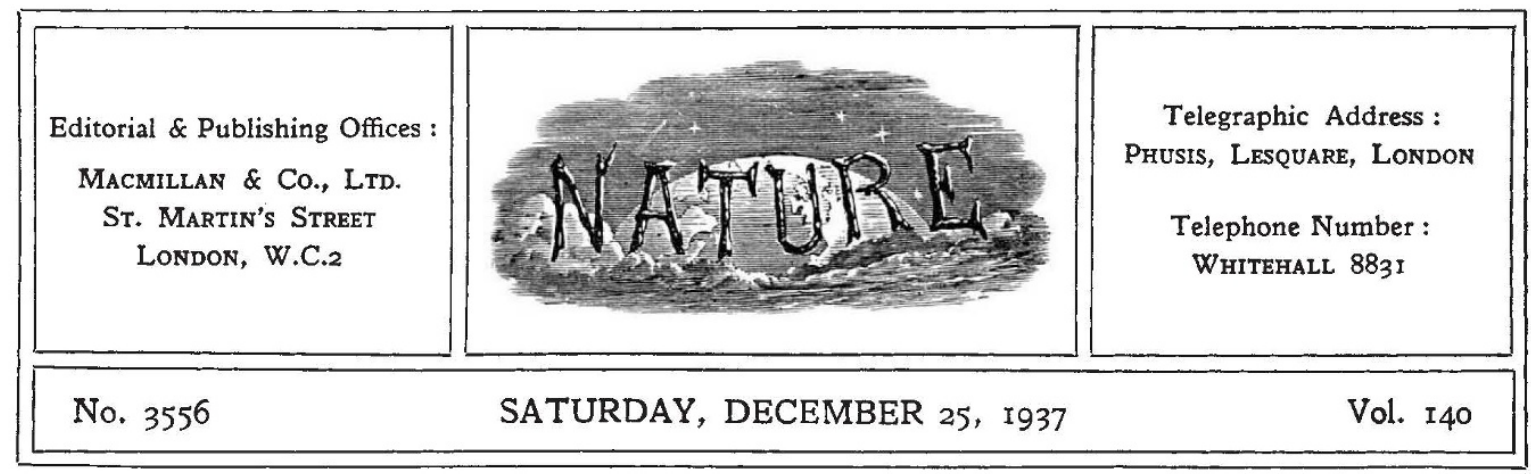

\title{
Location of Industry in Great Britain
}

$\mathrm{T}$ HE astonishment and uneasiness with which the evidence given by the Board of Trade to the Royal Commission on the Geographical Distribution of the Industrial Population at its fourth meeting has been received is an indication of how far the old ideas of laissez-faire have been left behind. The policy of do-nothing which the Board apparently follows is as unsuited to the present day as it is inconsistent with the general tenor of the Government's active intervention for the promotion of industrial and social well-being. Already Government policy is influencing the location of industry in many indirect as well as direct ways. The making of the Great West Road out of London, the electricity 'grid', the transference of workers, and the housing subsidy are some of the means already used to direct the location of industry away from old to new industrial areas, and are sufficient in themselves to invalidate the complacent view put forward by the Board of Trade.

The whole problem is one to which scientific workers may well give their attention; and welcome evidence that they are doing so is afforded by the meeting recently devoted by the Institution of Chemical Engineers to the Special Areas of England and Wales, at which Mr. C. H. Boyd gave an account of some technical and economic aspects of the Commissioner's work.

Mr. Boyd's survey showed clearly the great progress which has been made in the Special Areas in improving the local services in co-operation with the local authorities and other similar bodies. Arrangements have been made in all the areas whereby the industrialist can be provided, by the trading estates companies in the north-east and in South Wales and by the Industrial Development
Company in West Cumberland, with up-to-date factories of standard type either on the trading estates themselves or by arrangement with the Commissioner in other parts of the areas. The new policy of industrial development is already showing encouraging results, and is assisted by the fact that the areas are now in a position to provide a much more attractive market for the new and lighter industries than they have been for some years.

If there is a defect in Mr. Boyd's paper, it is that, before a technical audience, he made no reference in an otherwise comprehensive bibliography to the admirable report on Science and Industry of the Joint Committee of the Local Sections of the Society of Chemical Industry, the Institute of Chemistry and the Chemical Society submitted to the District Commissioner in May 1935. This is the more regrettable because the preliminary step to the development of new industries must be research of this kind, and of the type undertaken by Prof. Marquand and his colleagues in South Wales-the application of scientific principles of industrial location to the facts of the distressed areas. We must know precisely what industries can be located profitably in the areas, and what industries can, in general, be located with equal success anywhere.

The improvement which has already taken place in the areas, and the fact that the manufacturer need no longer hesitate to try his fortune in them, should not lead us to overlook the fact that essentially recovery has revealed the bare bones of the problem. It is serious enough that more than $1,300,000$ persons should be out of work at the height of prosperity. It is even more disturbing that the burden of unemployment should still 
be heavily localized in the distressed areas. The major social problem persists in all the Special Areas. Their industries have in part been scaled down and rationalized, but their labour forces, amenities and facilities are still those designed for the old order when the markets of the world were open.

It is to this aspect of the question that Mr. Donald Tyerman directs attention in a trenchant article in Lloyd's Bank Monthly Review. Current conditions of recovery and rearmament have, for the time being, largely solved the cyclical problem. The special and more fundamental problems remain, intensified by the accumulation of derelict people and places, although the liquidation of the areas by scaling down and labour transference has commenced. Recovery in the Special Areas has in fact shown us that we must be prepared for distress at least as severe as ever in the next depression, or we must very considerably accelerate the development in them of new industries.

This is not to invalidate the solutions which are already being attempted : the maintenance of the maximum volume of staple exports by a liberal trade policy, and, if need be, by special aid, to reduce the difficulties of adjustment and liquidation to a minimum; the scaling down of equipment, capacity and labour forces to the maximum which can be employed in the staple industries, involving further extensive reorganization of the coal, cotton and iron and steel industries; and the mitigation of distress by curing, cleaning up and caring for human wastage, by special treat- ment for aged unemployables and young untrained unemployed. These remain as essential, but the establishment of new industries requires much closer investigation than it has yet received.

It is natural to expect that the Royal Com. mission on industrial distribution will become acquainted with much of the data and proposals available. Armed with this knowledge, the Government, with the assistance of business men, industrialists and technicians, will be in a position to act. It will at least continue its policy of fixing a magnet in the Special Areas which will overcome such attractions of London and the south as are not based upon their essential requirements or on well-founded economic considerations. If, however, it is to go further by increasing the inducements to new industries in the distressed areas, by multiplying trading estates and increasing the moneys available to the Special Commissioners and the Special Areas Reconstruction Association and by guiding or controlling much more vigorously than hitherto the location of industry, it will need in increasing measure the co-operation of scientific workers. They must accept the responsibility for some measure of the basic work required. The position which many men of science now take in industrial leadership and development places upon them, individually and through their professional associations, the further responsibility for that informed, impartial and creative criticism which is of vital importance to a democratic Government.

\section{A Chemical Encyclopædia}

Thorpe's Dictionary of Applied Chemistry By Prof. Jocelyn Field Thorpe and Dr. M. A. Whiteley. Fourth edition. Vol. 1: A-Bi. Pp. xxvii +703 . (London, New York and Toronto : Longmans, Green and Co., Ltd., 1937). $63 s$. net.

$\mathrm{T}$ HE appearance of a new edition of "Thorpe" arouses mixed feelings. Chemists will welcome what they know will be a lucid exposition of the latest information regarding a host of chemical subjects, compiled by experts, but this welcome must be tempered by the fact that the authors state it will be nine years before the last volume is to appear, and, since it is, unfortunately, impracticable to draw up an index in advance, it will be nine years before it is possible to ascertain with any facility what are the contents of the nine volumes. By that time, the present volume will be out of date and, presumably, steps will be taken to issue another edition; in other words, the "Dictionary of Applied Chemistry" is to become a periodical. This method of issue, no doubt, simplifies the work of the publishers, and, possibly, appeals to librarians who prefer to spread their slender monetary resources over a period of years, but it does not yield the best type of book from the user's point of view. 